\title{
La aljama de los judíos de Huesca a fines del siglo XV: una nómina de casatenientes de la judería de 1475
}

Eugenio BENEDICTO GRACIA

En el trabajo que vengo realizando desde hace varios años en el Archivo Histórico Provincial de Huesca, consistente en volcar toda la información referida a la aljama judía oscense entre 1391 y 1492 a partir de la consulta de los centenares de volúmenes de protocolos notariales conservados (que contienen un heterogéneo material de comandas, albaranes, juras, comercio de lanas, pieles, etc.), he encontrado una serie de documentos que no pueden ser clasificados de una manera sistemática. Son, sin embargo, de gran interés para conocer la vida privada de los judíos, como los testamentos y actas notariales de defunción, transacciones de campos, viñas y casas, obras en las sinagogas, referencias al baño de las mujeres, o informaciones sobre violencias y bandos en la aljama, etc. Por ello, he creído que podría ser útil ir editando aquellos que por su singularidad puedan resultar de mayor interés.

Publico a continuación una nómina de casatenientes de la judería, es decir, propietarios judíos de casas, correspondiente al año 1475, que puede tener un doble interés, demográfico y onomástico, para nuestro conocimiento de la aljama oscense durante el último periodo de su existencia. Federico Balaguer señalaba hace años, siguiendo

Sefarad 63 (2003) págs. 227-236

(C) CSIC

ISSN 037-0894 
las directrices marcadas por David Romano, en sus apuntes introductorios al estudio de la demografía judía oscense bajomedieval, que sería «interesante... la publicación de listas de judíos, sobre todo, si van acompañadas de referencias tributarias. Hasta ahora, los archivos oscenses no nos han proporcionado documentos de este tipo, pero incluso las listas que carecen de datos económicos pueden ser útiles, pues nos dan idea del desarrollo de las familias judías, de su persistencia en una determinada aljama y de sus emigraciones» ${ }^{1}$. Y es que, hasta este momento, los datos de fuegos con finalidad fiscal estudiados por Balaguer solamente nos daban el número, sin especificar los nombres de los vecinos.

Esta «nómina de las casas de bezinos habitadores de la ciudad de Huesca, casa por sí teniente en aquella de cristianos legos, jodios e moros» de 1475 está contenida en el protocolo $n^{\circ} 155$ del notario Antonio Bonifant, y detalla los nombres de todos los casatenientes cristianos (529), judíos (118) y mudéjares (35), con un total de 682 nombres. Desconozco -porque la evidencia documental no me ha permitido averiguarlo- la finalidad de esta nómina, probablemente en relación a alguna derrama fiscal. Por otra parte, no se debe olvidar que casateniente no equivale a vecino o «fuego», ya que podría referirse más bien a propietario de vivienda. Por un lado, quedan exentos de esta nómina clérigos y judíos francos, y por otro, también aquellos habitantes que no fueran propietarios. Tenemos, por lo tanto, un número mínimo de vecinos.

Desde el punto de vista cuantitativo, esta cifra confirma las noticias acerca del número aproximado de judíos de Huesca a lo largo de la segunda mitad del siglo XV, que rondaría los 500, lo que la sitúa como segunda aljama en importancia, junto con Calatayud, del reino de Aragón ${ }^{2}$. Un contraste con el censo de casas realizado en

1 F. Balaguer, «Notas sobre la población judía en el siglo XV», Sefarad 45 (1985) págs 341-352.

2 F. BAlaguer, «Notas sobre la población judía», págs. 348-349. Balaguer menciona un recuento de casas realizado en 1462 en Huesca (sin especificar la fuente), con un total de 135 casas judías, número superior al de casatenientes de 1475 (583 de cristianos legos y 90 de moros). Por otro lado, los procuradores de 
1462 nos da una cifra sensiblemente inferior a esta última, aunque el cómputo de casas judías en 1462 y de casatenientes judíos en 1475 nos da un porcentaje similar en torno al 16-17 \% del total de la ciudad. En mi opinión, aunque este dato puede acercarse a la realidad, deberá ser contrastado y matizado con la información que se desprende de las comandas o deudas que los judíos contraen con los cristianos, dejando como prenda o aval, casi en su totalidad, su propia casa, ya que allí nos encontramos con que algunos son sólo propietarios de la mitad o un tercio de la vivienda. Supongo, por ello, que este «censo» encubría algunas familias que habitaban en la misma casa.

También habrá que tener en cuenta las viviendas de conversos que salían de la judería a vivir con cristianos, pero que dejaban en «trehudo» su antigua vivienda a otros judíos. Creo que podré, en parte, concretar este extremo, utilizando dicha evidencia documental que ya estoy analizando. Por su parte, Antonio Durán recurría a las reuniones de la aljama, según actas de 1393 y 1492, llegando a la conclusión de que podría haber en torno a 150 familias judías en la ciudad $^{3}$. No obstante, el número de asistentes a esas reuniones es muy variable, aun en plazos de tiempo muy cortos, ya que dispongo de varias actas de elección de oficiales de la aljama; así, en las de 1472 y 1474 aparecen citados, respectivamente, 130 «redolinos ${ }^{4} » \mathrm{y}$ $30 \ll$ redolinos».

Me ha animado a publicar este «censo urbano» el hecho de haber llegado al año 1483 y, tras revisar todos los protocolos notariales desde 1391, ser éste el único documento de estas características encontrado. No parece posible que en los pocos años que restan

\footnotetext{
la aljama en 1492 estiman en torno a 500-600 el número de judíos expulsados de la ciudad.

3 A. Durán Gudiol, La judería de Huesca (Zaragoza 1985) pág. 44.

${ }^{4}$ Los redolinos son bolitas con un horado en el que se introduce una cédula con el nombre de la persona que ha de entrar en un sorteo, en este caso para la nominación de cargos de la aljama. Como se ve, el número de participantes en tales sorteos es muy variable.
} 
hasta 1492 pueda surgir alguno más ${ }^{5}$. Ni Ricardo del Arco ni Federico Balaguer dan noticia del hallazgo de este tipo de documentos a pesar de ser el período más investigado por ellos ${ }^{6}$.

La nómina de los casatenientes está precedida por el encargo del prior y jurados de la ciudad de Huesca. Una vez realizada la pesquisa, la pasan al notario Antón Bonifant para que la complete «nombre por nombre». Es de suponer que en la confección de la nómina de casatenientes judíos participara el clavario de la aljama, que era el encargado usual de efectuar los repartos fiscales. La relación empieza en una columna con los «moros» (f. 105r), seguidos en la segunda columna del mismo folio por los «cristianos legos», encabezándose por «dentro muro l'alquibla» (es decir, la morería), para intercalar la relación de «judería»; de nuevo sigue la lista de «cristianos legos» (de f. 106r al final), agrupada por barrios (Remián, Montaragón y Madalena), iniciándose el f. 108v con un epígrafe que dice «fuera muro», el cual podría darnos la clave de que se trataba de los ciudadanos no censados por estar fuera de la ciudad propiamente dicha. Con los datos disponibles no puedo afirmar si la relación se hizo siguiendo el orden de las propias carreras públicas, aunque esta sugerencia no se aparte, quizás, de la realidad.

\section{LOS JUDíOS DE HUESCA A FINES DEL SIGLO XV}

Tras una lectura inicial de la nómina, me ha sorprendido la ausencia en ella de una serie de nombres que alcanzarán trágico renombre en la aljama oscense en sus últimos años de existencia en relación a los procesos inquisitoriales contra la aljama y el auto de fe de 1489 , y que sabemos que eran vecinos de Huesca ${ }^{7}$. Concretamente, están

\footnotetext{
${ }^{5}$ En el momento de revisión de las pruebas de este artículo, he completado la consulta de los protocolos hasta 1492 y no he encontrado nóminas similares.

6 R. DEL Arco y Garay, «La aljama judaica de Huesca», Sefarad 7 (1947) págs. 271-301; R. DEL ARCO Y GARAY y F. BALAGUER, «Nuevas noticias de la aljama judaica de Huesca», Sefarad 9 (1949) págs. 351-393.

7 Acerca de este episodio, vid. A. DuRÁn Gudiol, La juderia de Huesca, págs. $114-127$ y $169-173$.
} 
ausentes los rabíes Jucé Papur, Abraham Bivach, Mosé Arrondí o Abraham Almosnino (sin embargo, sí incluye un Almosnino, 28), así como maestre Açach Bivach, y los sastres Mosé Cohén o Hayim Fichel, ausencia debida, quizás, a su exención fiscal. Sí es posible identificar, no obstante, otros individuos implicados en dicho episodio, como rabí Abraham Alintienz (šamaš de sinagoga; quizás, uno de los tres homónimos en 33, 76 y 89), que asiste a la pretendida ceremonia de circuncisión de Juan de Ciudad; Jacó Xuén (60); rabí Acach Alcucunbriel (73); y el mercader Carhea (Azarián) Xuén (102).

Una segunda característica es la continuidad de ciertas familias a lo largo de los siglos XIV y XV. Es el caso de los Surí (82, 107, 108), magistralmente estudiados por David Romano ${ }^{8}$. Y además, familias adineradas a fines del siglo XV, como los Xuén (Šua ib): Jacó (60), Carhea, mercader (102), Mosé (15), Simuel, mayor, trapero (103) y Simuel, menor, zapatero (105), hijo de Jucé, que se convierte en 1492. O los Argelet, Bonafós y Gentó (10 y 11), Acach (49) y Abram (52).

Una imagen sincrónica de los miembros más pudientes de la aljama nos la da la lista de catorce judíos que actúan como garantes del censo que la aljama de Huesca vende en 1472 al mercader Alfonso Gómez y que publicara Durán ${ }^{9}$. Todos ellos aparecen mencionados en la nómina realizada tres años después $(55,98,49,52,11,5,46$, $60,102,103,105,15,74$ y 101), entre ellos los dos adelantados, don Samuel Lo Nieto (55) y Salomón de las Infantas (98), junto con Jucé Raenas (31), también adelantado, representado por su lugarteniente Jucé Gabay (12). Únicamente cabría identificar, quizás, a «Bienvenido» (46) de nuestra nómina con el importante mercader Aym al-Tortoxí, adelantado en 1492. También aparece citado en el censo de 1472 el procurador de la aljama Acach Ayeno, alias Orellana (86), alias relativo a su profesión de corredor de oreja. Dicho censo nos permite identificar otros personajes de la nómina, como [Gentó] Farfé (8). Otro individuo que aparece es Abram Albaclí (62), rabí y escribano de la aljama.

\footnotetext{
${ }^{8}$ D. Romano, «Los Surí, judíos de Huesca y perleros de la reina de Aragón (1350¿1372?)», Sefarad 40 (1980) págs. 255-281.

9 D. Romano, «Los Surí, judíos de Huesca», págs. 163-168.
} 
Por último, cabe destacar la abundancia de maestres (médicos) mencionados en la nómina, hasta cinco $(29,56,57,74,101)$, así como viudas $(53,54,64,66,80,81,82)$. De entre estas últimas, no deja de ser relevante la mención a «las biudas d'Ezra Cocuf» (53), expresión cuyo significado no he logrado desentrañar hasta ahora a partir de la evidencia documental que he reunido. Alguien podría pensar en el sentido de matrimonio polígamo, pero parece que los judíos de Aragón rechazan esta práctica social ya desde el siglo XIII.

\section{APÉNDICE DOCUMENTAL ${ }^{10}$}

\section{5, abril 19. Huesca}

Antón de Alquézar, jurado de Huesca investiga, por mandato del prior y jurados de la ciudad, la nómina de las casas de vecinos, judíos, cristianos, legos y eclesiásticos, y mudéjares y ordena ponerla por escrito.

AHPH, protocolo $n^{\circ} 155$ (notario Antonio Bonifant), ff. 104r, $105 v-106 r$

[f. 104r] In Dey nomine amen. Noverint universi quod anno a Nativitate Domini $\mathrm{M}^{\circ}$ CCCC LXXV, día yes a saber que se contava a diz e nou del mes de abril en la ciudat de Huesca, presentes mí, notario et los testimonios diuso escriptos, Anthón de Alquecar, ciudadano e jurado delante dita ciudad. De ordinación de los senyores prior y jurados de la dita ciudat, investigo la nómina de las casas de los bezinos e habitadores de la ciudad de Huesca, casa por sí tenientes en aquella, de eclesiásticos, legos, jodíos y moros, e la mandó escribir e continuar a mí, notario infrascripto e yes la dita investigación segunt se sigue. Insertar la nómina de los casas tenientes.

\footnotetext{
${ }^{10}$ He mantenido la grafía que aparece en el documento, aunque he modernizado la puntuación, así como la acentuación de palabras. Es muy frecuente que el mismo nombre aparezca escrito de diversas maneras, incluso en el mismo documento. En todos los folios figuran los nombres escritos en tres columnas.
} 
Et despues feyta la dita investigación por el dito jurado, presentes mí, notario, e los testimonios infrascriptos e mandado a mí, dito notario, escrivir et continuar aquella, nombre por nombre segunt por el mesmo dito de suso, se parece dixo que requería segund que de feyto requirió a mí, notario infrascripto, que de la dita investigación e nominación e mandamiento por él a mí, dito notario, feito, fiziese e testificase carta pública una e muytas o tantas quantas necesarias fuesen, así al descargo de su officio como al ponderación de dita ciudad e clasificación de aquella.

Testimonios a las sobreditas cosas fueron presentes Johán de Longares et Anthón de Navallas, cap de guaytas de la ciudad de Huesca [...]

[f. 105v, columna 2]

[...] Judería

[1] Jacó Ardit

[2] Sentó Allaquén

[3] Mosé Ardit

[4] Aym Ardit

[5] Salamó Alegua

[6] Alfaguel

[7] L'otro Allegua

[8] Farfé

[9] Pastor

[10] Bonafós Argelet

[11] Gentó Argelet

[12] Jucé Gabbay

[13] Nohé Almatarén

[14] Falaguera mayor

[15] Mosé Xuén

[16] Falaguera menor

[17] Mosé

${ }^{11} i=n^{\circ} 22$ ?
[18] Abram Alcoquí

[19] Acach de Pina

[20] Ariçano

[2I] Jucé Natán

[22] Gentó Leví

[23] Nicim Cubero

[Un nombre tachado: Yontó Leuí ${ }^{11}$ ]

[24] Mayr Magallón

[25] Erica

[26] Erica

[27] Cabanyas

[28] Almosnino

[29] Maestre Sentó

[30] Jeudá Alintienz

[31] Jucé Raenas

[32] Aym Abuaxech

[33] Abrayme Alintienz 
[columna 3]

[34] Jentó Arueti

[35] Çacón

[tachado: maestre]

[36] Acach Magallón

[37] Acach Alguero

[38] Aym Anpasat

[39] Abadías el Luengo

[40] Mosé Bonoy

[41] Bonafós Parello

[42] Acach Magallón

[43] Nauaro

[44] Acach Cubero

[45] Salamón Nacán

[46] Bienbenido

[47] Semuel Magallón

[48] Acach Cap

[49] Acach Argelet

[50] Mosé Montanyés

[51] Abram Almaxech

[52] Abram Argelet

[53] Las biudas d'Ezra Cocuf

[54] La biuda d'Enín

[55] Semuel el Nieto

[56] Maestre Jucef d'Ixía

[57] Maestre Jucef Frad

[58] Acach Alintienz

[59] Salamón Alintienz

[60] Jacó Xuén

[61] Jacó de las Infantas

[62] Abram Albaclí

[63] Abinabez

[64] La viuda de Marco

[65] Jentó Abadías

[66] La viuda de Jacó Cohén [f. 106r, columna I ]

[67] Jucé Vsiello

[68] Salamón Alcucunbriel

[69] El fillo de Aburabe

[70] Eliezer Adder

[71] Jucé Natán

[72] Gentó el Castellano

[73] Acach Alcucunbriel

[74] Maestre Abram Vsiello

[75] Simuel el Nieto

[tachado: Jacó a]

[70] Abram Alintienc, menor

[77] Alazar Auín

[78] Salamón Alger

[79] Mosé Aybari

[80] La biuda de Latronay

[81] La biuda de maestre Mossé

[82] La biuda de Curí

[83] Cahadíhas Almaxech

[84] Jeudá Alcatalay

[85] Bonafós Alcucunbriel

[tachado: Salamón Anpinaz]

[86] Ayeno

[87] Jeudá Laros

[88] Mosé Anbrón

[89] Abram Alintienc

[90] Allaguén

[91] Mosé Elpén

[92] Carehea Alpalpén

[93] Gentó Alfrangil

[94] Samuel Ardit

[95] Abadía Arueti

[96] Jacó el Luengo

[97] Jeudá Adder 


\begin{tabular}{|c|c|}
\hline \multicolumn{2}{|c|}{ LA ALJAMA DE LOS JUDÍOS DE HUESCA A FINES DEL SIGLO XV } \\
\hline [columna 2] & [108] Jacó Curí \\
\hline [98] Salamón de las Infantas & [109] Aym Gastón \\
\hline & [110] Simuel Gastón \\
\hline [99] Josuas Pareno & [111] Astruch Muçanuno \\
\hline [100] Acach Parello & [112] Jucé Guneco \\
\hline [101] Maestre Astruch & [113] L'argentero \\
\hline [102] Carhea Xuén & [114] Salamó Adder \\
\hline [103] Simuel Xuén & [115] Mosé Auín \\
\hline [104] Jucé Cazez & [110] Calaorra \\
\hline [105] Simuel Xuén & [117] Salamó Anbrón \\
\hline [106] Daui Cazez & [118] Salamón Natán \\
\hline [107] Mahamén Curí & \\
\hline
\end{tabular}

\section{RELACIÓN ALFABÉTICA DE LOS APELLIDOS}

Abadías (65)

Abenabez (63)

Abinfanoca o De las Infantas (61, 98)

Ablatronel (81)

Abuaxech o Almaxech $(32,51,83)$

Aburrabe (69)

Adder $(70,97,114)$

Albaclí (62)

Alcatalay (84)

Alcocumbriel $(68,73,85)$

Alcoguí (18)

Alegua $(5,7)$

Alfaquel (6)

Alfrangil (93)

Alguero $(37,78)$

Allaquén $(2,90)$

Alintienz (33, 58, 59, 76, 89).

Almatarén (13)

Almosnino (28)

Anbrón $(88,117)$

Anín $(54,77,115)$
Anpasat (38)

Anpinaz (entre 85-86)

Ardit [¿Ardut?] $(1,3,4,94)$

Argelet (10, 11, 49, 52)

Ariçano, Erica $(25,26,20)$

Arrueti $(34,95)$

Aybari (79)

Ayeno (86)

Bienvenido [¿Al-Tortoxí?] (46)

Bonoy (40)

Cabanyas (27)

Calaorra (116)

Cap (48)

Castellano (72)

Cazez $(104,106)$

Cocuf (53)

Cohén $(66,101)$

Cubero $(23,44)$

El Nieto $(55,75)$

Elpén $(91,92)$ 
Falaquera $(14,16)$

Farfé (8)

Frad (57)

Gabay (12)

Gastón $(109,110)$

Guneco (112)

Ixía (56)

Laros (87)

Latronay (80)

Leví (22)

Luengo $(39,96)$

Marco (64)
Magallón (24, 36, 42, 47)

Muçanuno $(111, ¿ 113$ ?)

Natán $(21,45,71,118)$

Nauaro (43)

Parello $(41,99,100)$

Pastor (9)

Pina (19)

Raenas (31)

Çacón [Sassón] (35)

Çurí $(82,107,108)$

Usiello $(67,74)$

Xuén [ک̌̉ı aib $](15,60,102,103,105)$

\section{RESUMEN}

Edición y análisis de una nómina de judíos de la aljama de Huesca en 1475, procedente de un protocolo notarial de la ciudad, que nos permite conocer con mayor detalle esta importante comunidad judía del reino de Aragón en relación a la personalidad de alguno de sus miembros, así como realizar ciertas observaciones demográficas para el periodo anterior al decreto de expulsión.

Palabras ClaVe: Historia de los judíos, demografía, Aragón (Huesca), siglo XV.

\section{SUMMARY}

Edition and analysis of a document containing a nominal list of Jews of Huesca in 1475, one of the most important Jewish communities in the kingdom of Aragón in the period previous to the expulsion of 1492. This documentary evidence allows us to shed light on certain conspicuous members of the aljama, as well as on its demography.

KEYwORDS: History of the Jews, demography, Aragón (Huesca), $15^{\text {th }}$ century. 